\title{
ВЗРОСЛОЕ МУЗЫКАЛЬНОЕ ОБРАЗОВАНИЕ КАК ИМПЕРАТИВ МЕНЯЮЩИХСЯ РЕАЛЬНОСТЕЙ СОВРЕМЕННОГО ОБЩЕСТВА
}

Для многих преподавателей музыки, прошедших подготовку для обучения детей музыке, задача эффективно работать со взрослыми может вызвать смешанные чувства. Принимая во внимание эти реалии, очень важно учителям музыки, участвующим в музыкальных образовательных программах для взрослых, иметь свои стратегические приоритеты. Благодаря работе со взрослыми учениками, преподаватели музыки имеют возможность не только оказывать помощь им на пути достижения их цели обучения, но и вовлечь их к участию в исполнительском искусстве, а также активировать их как слушателей. Актуальным становится вопрос об информированности педагогов музыки проблемами взрослого образования.

Обычно учителя думают, что нет никакой разницы между тем, обучают ли они взрослых или детей. Педагоги в общих чертах используют одинаковые стратегии как для младших так и для взрослых учеников. Точка зрения любого учителя музыки касательно взрослого учащегося не сильно отличается от точки зрения венгерского композитора и прославленного педагога Золтана Кодаи, который выразил убеждение, что если не начать качественное музыкальное образование рано, то ученик будет полностью «потерян» музыкально. Он писал: «Лет от трех до семи гораздо важный этап в плане обучения, чем более позднее время. Что будет испорчено или опущено в этом возрасте не может быть исправлено позже. В эти годы решается практически будущее... Если душа остается необработанной в возрасте около семи, она уже не дает ничего, чтобы можно было бы впоследствии выращивать.» (Kodály 1941/1974: 129)
Однако новейшие исследования в области взрослого образования доказывают, что на взрослых, желающих заниматься музыкальной деятельностью и в частности играть на какомлибо инструменте, возлагаются немалые надежды. Учителя всевозможных методов обучения делают все, чтобы обеспечить «вход» или «возвращение» в музыкальную деятельность взрослым, чтобы вовлечь их в процесс своеобразной магии самоутверждения в музыкe.

Теория обучения взрослых представляется постоянно меняющейся мозаикой, где старые части перестраиваются в новые возможности. Пересматривая некоторые из этих «старых» частей и изучая новые, мы надеемся внести свой вклад в помощь преподавателям музыки в процессе расширения горизонтов в понимании, кто именно есть взрослые ученики, и как они представляют свое «запоздалое» музыкальное образование. Для этой цели

1. Мы начнем с рассмотрения мотиваций и причин учебы взрослых,

2. познакомимся с новейшими работами, в которых исследуются различия детского и взрослого образования,

3. предоставим идеи о том, как именно педагоги музыки могли бы работать со взрослыми, чтобы способствовать их оптимальной поддержке.

Мотивации взрослых к обучению. К.Хул был одним из первых исследователей изучавший ориентации и основные мотивации взрослых к обучению (Houle 1961/1993). В результате подробных интервью им были определены три вида мотивационных моделей среди взрослых. 
Во-первых, это те, которые представляют «целенаправленную» группу. В эту группу входят взрослые ученики, желающие получить образование для достижения конкретных целей. У таких учащихся определенные цели, для достижения которых они присоединяются к конкретному курсу или к конкретной группе.

Некоторые взрослые просто ориентированы на “деятельность", причины участия в которой могут не иметь явных связей с содержанием и целями деятельности. Например, они могут присоединиться к хору, чтобы встретиться с другими людьми, или принять участие в инструментальном ансамбле, потому что они хотят служить другим в местном сообществе, посетив, например, дом престарелых.

Третья категория включает тех взрослых, которые ориентированы «на образование». Участвуя в системе непрерывного образования, эти люди, как правило, стремятся к познанию ради желания развивать собственные знания и навыки.

Конечно же эти мотивации не всегда бывают «чистыми», и учащиеся могут продемонстрировать несколько мотиваций одновременно. Например они могут целенаправленно продолжить свое музыкальное образование для того чтобы углубить свои знания и навыки играть на каком-либо музыкальном инструменте, и вместе с тем-аккомпанировать церковному хору, тем самым служить своей общине, или же участвовать в обучении ради просто веселого времяпрепровождения. Возможно сочетание всех этих мотиваций вместе взятых. Исследования в области взрослого образования показывают, что учащиеся могут заниматься своим музыкальным образованием или вовлечь себя в какую-нибудь музыкальную активность по многочисленным и сложным причинам и что причины их мотиваций к обучению с течением времени могут меняться .

Различия между детским и взрослым образованием. Имеются многочисленные ис- следования изучающие различия между детским и взрослым образованием.

С.Мериам и соав. указывают, что конфигурации процессов обучения в детском и зрелом возрасте отличаются в ряде важных направлений: Это 1. ученики, 2. контекст, 3. процесс обучения (Merriam, Caffarella \& Baumgartner 2007).

Ученики. Детское и взрослое образование отличаются друг от друга существенным обра30M.

В то время как для ребенка обучение - это зачастую новый опыт, который прибавляется к предыдущему, хоть и маленькому опыту, у взрослого уже имеется жизненный опыт, который способствует его обучению. Психология определяет также различные этапы жизни, в которых пребывают дети и взрослые во время образования. Для детей - это этап развития доверия, самостоятельности, инициативности и независимости. Для взрослых - это этапы развития жизни, когда идентифицируются интимность, генеративность и целостность (Merriam, Caffarella \& Baumgartner 2007: 423-426). Кроме того, взрослая жизнь характеризуется жизненными событиями и переходами, резко отличающими от детских.

Это могут быть, например, задачи связанные с карьерой, семьей или с возрастом.

Учителя музыки могут использовать предыдущий опыт взрослых. Например, музыкальные воспоминания накопленные в течение жизни повышают способность взрослых к обучению музыке, а также способствуют ее верной интерпретации. Таким образом, взрослый ученик приносит свой опыт в процесс обучения музыки, который может быть использован преподавателем. Учителя могут также использовать предварительные знания взрослых, объясняя понятия и термины по отношению к предшествующим знаниям.

Контекст обучения. Есть несколько основных различий между контекстами обуче- 
ния у детей и у взрослых, которые могут быть использованы музыкантами педагогами.

Общеизвестно, что зависимость детей от других субъектов (напр. родителей) может привести к разным ограничениям образовательных возможностей. Это обстоятельство в меньшей степени относится к взрослым. Как независимые учащиеся, взрослые сами могут принимать самостоятельные и обоснованные решения, решить какие уроки брать, на каком музыкальном инструменте играть, или же выбрать себе педагога. Иначе говоря, взрослые гораздо чаще, чем дети, имеют средства и возможности принимать решения, касающиеся собственного образования в соответствии с их приоритетами и целями.

Кроме того, в то время как дети принимают участие в музыкальной деятельности в качестве обязательных мероприятий, взрослые включаются в образовательные возможности добровольно и тем самым проявляют энтузиазм и пылкое желание учиться. Другими словами, взрослые - это самостоятельно ориентированные ученики, которые могут брать на себя ответственность за то, что именно они хотят учить и как они собираются это организовать.

Как уже упоминалось, участие взрослых в процессе обучения происходит в то время, когда они параллельно решают задачи связанные с карьерой и семьей. В этом смысле участие в музыкальных программах может быть оценено как нечто совершающееся как для конкретных, так и для развлекательных целей.

Процесс обучения. С.Мериам и соав. Отмечают, что из трех отличий контекста обучения, в третьем налицо наименьшее количество различий между взрослым и детским образованием (Merriam, Caffarella \& Baumgartner 2007).

К.Хул утверждал, что процесс обучения у взрослых и детей вообще идентичный (Houle 1961/1993). М.Ноулс, сформулировавший ос- новные положения андрагогики (отрасль педагогической науки, раскрывающий теоретические и практические проблемы обучения, воспитания и образования взрослого человека в течение всей его жизни), напротив, утвежрдает, что в основе взрослого обучения лежат шесть основных принципов, отличающих его от детского обучения (Knowles, Holton \& Swanson 2005):

1. взрослому человеку, который обучается, - обучающемуся (а не обучаемому) принадлежит ведущая роль в процессе обучения;

2. он, являясь сформировавшейся личностью, ставит перед собой конкретные цели обучения, стремится к самостоятельности, самореализации, самоуправлению;

3. взрослый человек обладает профессиональным и жизненным опытом, знаниями, умениями, навыками, которые должны быть использованы в процессе обучения;

4. взрослый ищет скорейшего применения полученным при обучении знаниям и умениям;

5. процесс обучения в значительной степени определяется временными, пространственными, бытовыми, профессиональными, социальными факторами, которые либо ограничивают, либо способствуют этому;

6. процесс обучения организован в виде совместной деятельности обучающегося и обучающего на всех его этапах.

М.Ноулс различает два способа, в которых концептуализируется целенаправленная учеба.

1. "самонаправленное обучение», когда взрослый ученик «способен взять под свой контроль механику и методики собственного образования» (Knowles, Holton \& Swanson 2005: 185). 
2. "личная автономия", когда взрослый ученик берет на себя полную ответственность за планирование целенаправленных учебных задач для достижения своих целей.

Наиболее полной формой взрослого самонаправленного обучения является та, в которой ученик испытывает внутренние изменения в сознании, в результате внешнего управления учебных задач. Здесь самонаправленное обучение включает в себя критическое осмысление и рассмотрение альтернативов. Таким образом, внешние технические и внутренние рефлективные параметры самонаправленного обучения сливаются, когда взрослые приходят к пониманию природы знания как ценности, и когда они действуют на основе этой оценки для переосмысления и воссоздания их личных и социальных миров.

М.Ноулс сам представлял педагогику на континууме от «направленная преподавателем» к «направленная студентом".

Исследования показали, что стимул урока, осмысленность деятельности и мотивация к обучению - это те три фактора, которые особенно влияют на обучение взрослых.

Некоторые рекомендации учителям музыки работающими со взрослыми учениками.

1. Необходимо учесть тот факт, что для оптимального обучения взрослым необходимо знать причины, для чего тот или иной материал включен в урок .

2. Учителя могли бы рассмотреть вопрос, как именно помочь взрослым взять на себя инициативу собственного обучения и самостоятельно установить цели.

3. Учителя должны инициировать активность взрослых во время урока и выбора репертуара.

4. Надо учитывать тот факт, что если дети могут выучить материал на первый взгляд не так существенный в данный момент, взрослые хотят приобрести навыки и знания, значимые для них в данный отрезок времени для того чтобы применить их на практике.

5. Необходимо учесть корректировки темпов инструкций для того, чтобы обеспечить достаточное время взрослым для освоения новых навыков.

6. Взрослые вряд ли продолжат учебу, если их мотивации не будут поддержаны.

Заключение. В заключении хотелось бы суммировать ключевые идеи взрослого образования, которые могут быть применены музыкантами педагогами в своей профессиональной деятельности со взрослыми учениками:

- Мотивации взрослых учиться музыке обычно многогранны и сложны, и со временем могут меняться. Учителя музыки, которые работают со взрослыми должны рассмотреть вопрос как именно со временем менялись их собственные мотивации к обучению и как они сходны с ориентациями взрослых учеников.

- Обучение в зрелом возрасте отличается от детского обучения в ряде важных направлений, включающих контекст обучения, студента и процесса обучения. Взрослые ученики добровольно берутся за музыкальную деятельность как самостоятельные, автономные субъекты. Преподаватели музыки должны воспользоваться этими характеристиками, помогать и направлять их самостоятельно принимать обоснованные решения о том, что и как учить.

- В процессе обучения взрослые ученики основываются на своем жизненном опыте. Учителя должны воспользоваться музыкальными воспоминаниями взрослых учеников, по возможности включить в репертуар такие произведения с которыми они уже предварительно знакомы. 
- Учителя должны также принять во внимание детский музыкальный опыт взрослых учеников. В случае если эти переживания были отрицательными, или в тех случаях, если у взрослых появились при-

\section{ЦИТИРОВАННАЯ И УПОМЯНУТАЯ} ЛИТЕРАТУРА

3. Houle, C.O. (1961/1993). The inquiring mind: A study of the adult who continues to learn (3rd ed.).

4. Norman, OK: Oklahoma Research Center for Continuing Professional and Higher Education.

5. Knowles, M.; Holton, E.F.; Swanson, R.A. (2005). The adult learner: The definitive вычки, отрицательно сказывающиеся на новые знания, возможно, потребуется дополнительная поддержка или поощрение учеников для разработки новых способов мышления и занятий.

classic in adult education and human resource development (6th ed.). Burlington, MA: Elsevier.

6. Kodály, Z. (1941/1974). Music in the kindergarten. In Z. Kodály, The selected writings of Zoltán Kodály(pp. 127-151). London: Boosey \& Hawkes.

7. Merriam, S.B.; Caffarella, R.S.; Baumgartner, L.S. (2007). Learning in adulthood: A comprehensiveguide ( $3 \mathrm{rd}$ ed.). San Francisco, CA: Wiley.

\section{ВЗРОСЛОЕ МУЗЫКАЛЬНОЕ ОБРАЗОВАНИЕ КАК ИМПЕРАТИВ МЕНЯЮЩИХСЯ РЕАЛЬНОСТЕЙ СОВРЕМЕННОГО ОБЩЕСТВА}

\section{PЕЗЮMЕ}

Последние исследования в области взрослого образования доказывают, что взрослые, которые хотят быть активными в музыкальной деятельности или же играть на каком-нибудь инструменте, возлагают на это большие надежды. Теория взрослого образования кажется постоянно меняющейся мозаикой, в которой старые части превращаются в новое видение. В статье делается попытка изучить причины и мотивы образования взрослых, исследовать различия между детским и взрослым об- разованием, а также выдвинуть идеи о том, как учитель музыки может работать со взрослыми в целях содействия и оптимальной поддержки.

Ключевые понятия: образование для взрослых, подходы к обучению взрослых, мотивации учебы, мотивационные модели, контекст обучения, процесс обучения, самонаправленное обучение. 


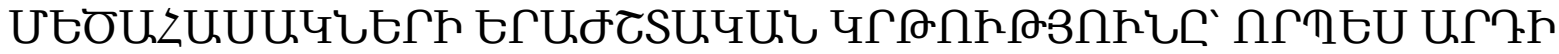

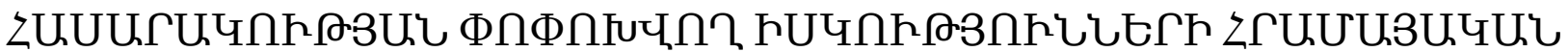

\section{UUФกФПЋU}

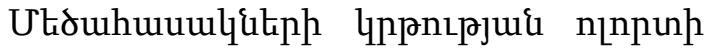

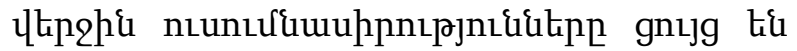
unußhu, np utiduhwumlqkipn, npnip guilnz-

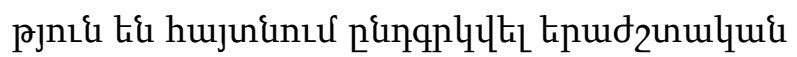

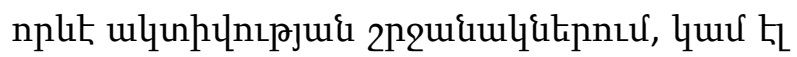
duluqkil nplet kpud2unuluer qnpohp, 2uun

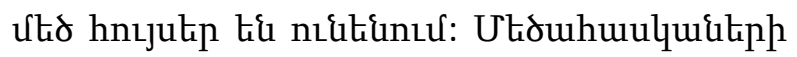

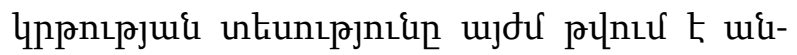
lthe hnuhnulnn ư unqupluu, nph hpq ưu-

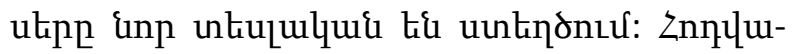

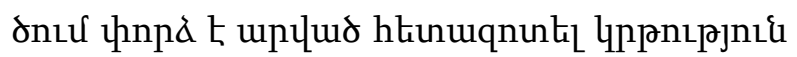

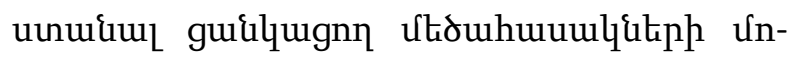

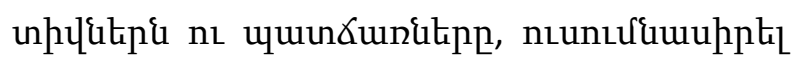

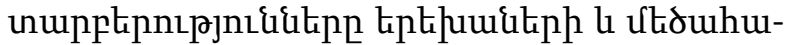

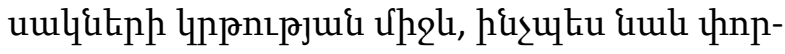

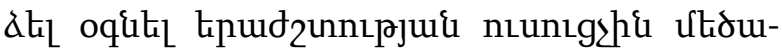

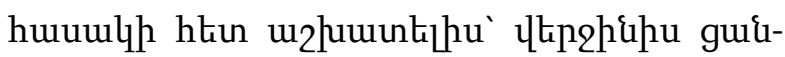

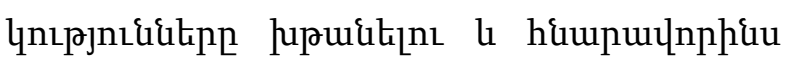

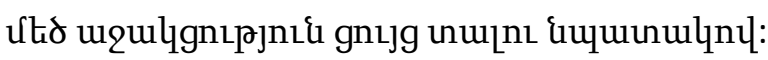

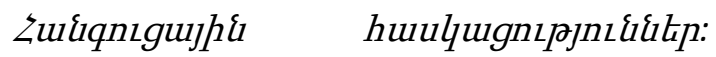

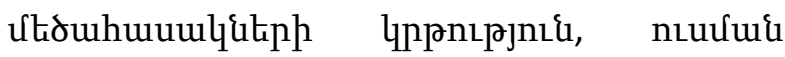

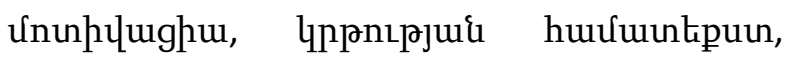

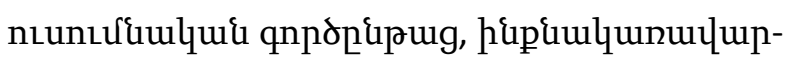
ไnn nıunıu:

\section{ADULT MUSIC EDUCATION AS AN IMPERATIVE OF CHANGING REALITIES OF MODERN SOCIETY}

\section{SUMMARY}

The latest research in the field of adult education prove that adults wishing to engage in musical activities and in particular to play a musical instrument are pinned high hopes. Adult learning theory seems ever-changing mosaic, where the old parts are transformed into new vision. In the article there is an attempt to study the causes and motivations of adult education, investigate the differences of children's and adult education as well as provide ideas on how music teachers could work with adults to promote them optimum support.

Key concepts: adult education, causes and motivations of adult education, context of education, the process of education, self-directed learning. 